\title{
Characteristics of Drug Overdose in Young Suicide Attempters
}

\author{
Yong-Sil Kweon ${ }^{1}$, Sunyoung Hwang ${ }^{1}$, Bora Yeon ${ }^{1}$, Kyoung Ho Choi ${ }^{2}$, Youngmin $\mathrm{Oh}^{2}$, Hae-Kook Lee ${ }^{1}$, Chung Tai \\ Lee', Kyoung-Uk Lee
}

Departments of ${ }^{1}$ Psychiatry and ${ }^{2}$ Emergency Medicine, Uijeongbu St. Mary's Hospital, The Catholic University of Korea College of Medicine, Uijeongbu, Korea

\begin{abstract}
Objective: Few studies have focused on the characteristic features of drug overdose in children and adolescents who have attempted suicide in Korea. The present study examined the characteristics of drug overdose in children and adolescents who visited the emergency room following drug ingestion for a suicide attempt.

Methods: The medical records of 28 patients who were treated in the emergency room following a drug overdose from January 2008 to March 2011 were analyzed. Demographic and clinical variables related to the suicide attempts were examined.

Results: The mean age of the patients was 16.6 1.7 years (range 11-19 years), and 20 of the patients (71.4\%) were female. Most of the patients ( $n=23,82.1 \%$ ) overdosed on a single drug; acetaminophen-containing analgesics were the most common $(n=12,42.9 \%)$. Depression was the most common psychiatric disorder ( $n=22,78.6 \%)$, and interpersonal conflict was the most common precipitating factor of the suicide attempts $(n=11,39.3 \%$ ). This was the first suicide attempt for approximately $80 \%$ of the patients. About one fourth of the patients $(n=7,25 \%)$ had follow-up visits at the psychiatric outpatient clinic.

Conclusion: Early screening and psychiatric intervention for depression may be an important factor in preventing childhood and adolescent suicide attempts. Developing coping strategies to manage interpersonal conflicts may also be helpful. Moreover, policies restricting the amount and kind of drugs purchased by teenagers may be necessary to prevent drug overdose in this age group.
\end{abstract}

KEY WORDS: Suicide; Overdose; Childhood; Adolescence.

\section{INTRODUCTION}

Suicide is a leading cause of death among children and adolescents in many countries. ${ }^{1,2)}$ The World Health Organization estimated that suicide was the second highest cause of mortality in 10-24-year-olds, and the rate continues to increase. The Centers for Disease Control and Prevention reported an $8 \%$ increase in suicide among youths in the US, the largest 1 -year increase in 15 years. ${ }^{3)}$ This large worldwide challenge requires a multilateral approach and more prevention studies.

Many previous studies have investigated the epidemiological phenomena and the risk factors associated with suicidal behavior. Tang et al. ${ }^{4)}$ investigated 10,233 adolescent students in southern Taiwan and reported that varia-

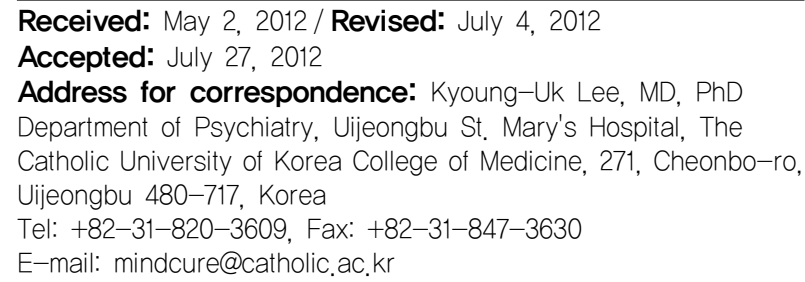

bles including female gender, weekly alcohol use, illicit drug use, depression, significant family conflict, poor family functioning, reduced interest in school, low rank in school, low acceptance in the peer group, and dropping out of school are associated with adolescent suicide attempts. In Finland, where youth suicide rates are among the highest in the world, Lahti et al. ${ }^{5)}$ investigated suicides in individuals under 18 years of age from 1969 to 1989 . A significant increase in more lethal suicide methods (e.g., hanging) among young females was noted, and the authors suggested that alcohol consumption, depression, and outward-directed violent behavior may be associated with suicide. ${ }^{5)}$ In a study on suicide rates in England and Wales conducted from 1970 to 1998, suicide rates among 15-19year-old males increased substantially between the 1970s and the 1990s. These results were associated with an increase in hanging and self-poisoning with vehicle exhaust gas in the 1980s, both of which continued to increase into the 1990s. ${ }^{6)}$ The change in suicide attempt methods has directly affected suicide rates. In the US, substantial changes in suicide methods have occurred in youths, particularly among females. From 2003 to 2004, rates of suicide

(c) This is an Open-Access article distributed under the terms of the Creative Commons Attribution Non-Commercial License (http://creativecommons.org/licenses/by-nc/3.0) which permits unrestricted non-commercial use, distribution, and reproduction in any medium, provided the original work is properly cited. 
rates from hanging/suffocation in females aged 10-14 years increased by $119 \% .^{7)}$ Despite the overall results of these studies, the typical characteristics of suicidal behavior in youths have yet to be clearly defined.

In Korea, few studies have investigated the characteristics of drug overdose and suicidal behavior by age group. Lee $\mathrm{et} \mathrm{al}^{8}{ }^{8}$ investigated the risk factors of suicidal behavior in college students and concluded that depression, probability of bipolar disorder, and academic achievement were the most important predictors of suicide ideation. The identified risks for suicide attempts were socioeconomic status and probability of bipolar disorder in their study. Kim et al..$^{9)}$ examined self-poisoning in the elderly and found that older individuals tended to choose more lethal suicide methods (e.g., pesticides) compared with young people. Im and $\mathrm{Kim}^{10)}$ found four core component of the meaning of suicide in older people: conflict with family, powerlessness and despair about their lives, decline in self-esteem, using internal and external resources to resolve their troubles, and awareness of an imminent crisis.

A few studies in Korea have examined drug overdose in children and adolescents. Kim ${ }^{11)}$ investigated 122 adolescents who visited the emergency room for accidental or intentional drug poisoning. Analgesics were to the most common drugs used for intentional self-poisoning, whereas pesticides were the most common drugs in cases of accidental ingestion. However, this study included both accidental and intentional poisoning and focused on the medical, not the psychological aspects of suicidal behavior.

The present study examined the pattern of drug overdose and the characteristics of children and adolescents who attempted suicide by drug overdose in Korea.

\section{METHODS}

\section{Subjects}

Data were obtained from a retrospective medical and psychiatric chart review of patients who were admitted to emergency room at Uijeongbu St. Mary's Hospital, the Catholic University of Korea, from January 2008 through March 2011.

Of the 30 patients who were treated in the emergency room following a drug overdose, two children who overdosed by mistake were excluded. Therefore, data from 28 patients were analyzed.

\section{Assessments}

Age, sex, past psychiatric history, number of previous suicide attempts, impulsivity of suicide attempts, precip- itating events, and the type of drug used were evaluated. Psychiatric evaluation and diagnosis were carried out by psychiatry residents using the criteria from the Diagnostic and Statistical Manual of Mental Disorders-IV Text Revision. ${ }^{12)}$ The patients were assessed in the emergency room using the Brief Emergency Room Suicide Risk Assessment (BESRA), which was constructed by the authors and has been explained elsewhere in detail. ${ }^{9)}$ In brief, the BESRA consists of domains related to the patient's demographic factors, clinical diagnosis, and psychiatric resources, as well as detailed information about the present suicide attempt including the method of suicide attempt, whether the attempt was planned or impulsive, the reason for the attempt, and risk and rescue rating scores. To measure the medical severity of the suicide attempts, the appropriate section of the Suicide Attempt Self-Injury Interview developed by Linehan et al. ${ }^{13)}$ was used. The scores used to measure medical severity ranged from 1 to $6(1=$ very low, $2=$ low, $3=$ moderate, $4=$ high, $5=$ very high, $6=$ severe). The risk/rescue rating scale developed by Weisman and Worden ${ }^{14)}$ was used. The risk and rescue ratings consisted of five variables used to assess risk (i.e., the method used and the actual damage sustained during a single attempt) and five variables to assess the likelihood of rescue (i.e., the observable circumstances and available resources present at the time of the attempt). The institutional review board approved this study.

\section{Statistical Analysis}

Demographic and clinical variables were summarized and are presented as mean \pm standard deviation or as frequency and percentage depending on the type of variable. All statistical analyses were performed using SAS/PC version 9.2 (SAS Institute Inc., Cary, NC, USA).

\section{RESULTS}

\section{Demographic and Clinical Characteristics}

Table 1 shows the overall characteristics of the patients. The mean age of the patients was $16.6 \pm 1.7$ years (range 11-19 years). Most of the subjects $(\mathrm{n}=26,92.8 \%)$ were adolescents over age 13 . Twenty patients $(71.4 \%)$ were female, and 8 (28.6\%) were male. The female-to-male ratio was $2.5: 1$. Depression was the most common psychiatric disorder $(\mathrm{n}=22,78.6 \%)$ among the patients, and adjustment disorder was the second $(\mathrm{n}=2,7.1 \%)$. Six (21.4\%) patients reported a past history of psychiatric disorders. 
Table 1. Demographic and clinical characteristics of the suicide attempters

\begin{tabular}{|c|c|}
\hline Characteristic & Mean $\pm S D$ or $n(\%)$ \\
\hline Age (years) & $16.6 \pm 1.7$ \\
\hline \multicolumn{2}{|l|}{ Sex } \\
\hline Male & $8(28.6)$ \\
\hline Female & $20(71.4)$ \\
\hline \multicolumn{2}{|l|}{ Psychiatric diagnosis } \\
\hline Depression & $22(78.6)$ \\
\hline Adjustment disorder & $2(7.1)$ \\
\hline Unknown & $4(14.3)$ \\
\hline \multicolumn{2}{|l|}{ Psychiatric history } \\
\hline Yes & $6(21.4)$ \\
\hline No & $22(78.6)$ \\
\hline \multicolumn{2}{|l|}{ Ingested drugs } \\
\hline Acetaminophen & $12(42.9)$ \\
\hline Antihistamine & $6(21.4)$ \\
\hline Aspirin & $6(21.4)$ \\
\hline Pesticide & $2(7.1)$ \\
\hline Hydrocarbon & $1(3.6)$ \\
\hline Antidepressants & $1(3.6)$ \\
\hline \multicolumn{2}{|l|}{ Precipitating events } \\
\hline Interpersonal conflict & $11(39.3)$ \\
\hline Interpersonal loss & $1(3.6)$ \\
\hline Academic stress & $4(14.3)$ \\
\hline Physical illness & $1(3.6)$ \\
\hline Parental separation/divorce & $1(3.6)$ \\
\hline Other & $8(28.6)$ \\
\hline Unknown & $2(7.1)$ \\
\hline \multicolumn{2}{|l|}{ Number of previous suicide attempts } \\
\hline 0 & $20(71.4)$ \\
\hline 1 & $7(25.0)$ \\
\hline$\geq 2$ & $1(3.6)$ \\
\hline \multicolumn{2}{|l|}{ Impulsivity } \\
\hline Impulsive & $22(78.6)$ \\
\hline Planned & $5(17.9)$ \\
\hline Unknown & $1(3.6)$ \\
\hline \multicolumn{2}{|l|}{ Regret } \\
\hline Yes & $14(50.0)$ \\
\hline No & $7(25.0)$ \\
\hline Unknown & $7(25.0)$ \\
\hline Medical severity of index suicide attempt & $3.1 \pm 1.0$ \\
\hline \multicolumn{2}{|l|}{ Risk rescue rating scores } \\
\hline Risk-rating score & $7.5 \pm 2.0$ \\
\hline Rescue-rating score & $12.1 \pm 2.4$ \\
\hline \multicolumn{2}{|l|}{ Psychiatric outpatient clinic follow-up } \\
\hline Yes & $7(25.0)$ \\
\hline No & $21(75.0)$ \\
\hline
\end{tabular}

$\mathrm{SD}$, standard deviation.

\section{Ingested Drugs}

Most of the patients $(n=23,82.1 \%)$ overdosed using a single drug. Acetaminophen-containing analgesics were the most common drugs used $(n=12,42.9 \%)$. Aspirin and antihistamines (e.g., diphenhydramine, doxylamine) were the second-most common $(n=6,21.4 \%$; $=6,21.4 \%$, respectively). Other drugs were pesticides $(n=2,7.1 \%)$, hydrocarbons $(n=1,3.6 \%)$, and antidepressants $(n=1,3.6 \%)$.

\section{Precipitating Events of Suicide Attempt}

Interpersonal conflict was the most common precipitat- ing event for the suicide attempt $(\mathrm{n}=11,39.3 \%)$; academic stress was second $(\mathrm{n}=4,14.3 \%)$. Interpersonal loss, physical illness, and parental separation/divorce were also reported as precipitating events by three patients $(\mathrm{n}=1$ each, $3.6 \%$ ). Other causes included feelings of hopelessness, feelings of exhaustion, and avoidance of legal problems.

\section{Suicide Behavior}

Twenty patients (71.4\%) attempted suicide for the first time, and about one-third of the patients $(28.6 \%)$ reported multiple suicide attempts. Most patients (78.6\%) attempted suicide impulsively, but some patients (17.9\%) had planned the suicide attempt. Fourteen patients $(50 \%)$ regretted their attempts, whereas 7 (25\%) denied any regret. The mean medical severity score was $3.1 \pm 1.0$, the mean risk rating score was $7.5 \pm 2.0$, and the mean rescue rating score was $12.1 \pm 2.4$. About one fourth of the patients $(n=7$, $25 \%$ ) had follow-up visits at psychiatric outpatient clinics.

\section{DISCUSSION}

The present study showed the characteristic features of drug overdose among youths who attempted suicide in Korea. In the current study, most of the subjects used a single drug as the method of suicide. Acetaminophen-containing analgesics, aspirin, and antihistamines (e.g., diphenhydramine, doxylamine) were the most commonly used drugs. These drugs are inexpensive and readily available at local pharmacies without any prescription or restriction in Korea. Moreover, popular use among the general population might make the patients insensitive to the risk of these drugs. Indeed, many studies have revealed that even among adults, Tylenol (Janssen Korea, Hwasung, Korea) is used frequently without accurate knowledge ${ }^{15)}$ of the risks involved. ${ }^{16)}$ Such findings emphasize the significance of drug accessibility in the choice of drugs for suicide attempts among children and adolescents.

The pattern of drugs used for suicide attempts is quite different from that found in older people in a previous study. ${ }^{9)}$ Elderly patients tended to ingest more lethal drugs, especially pesticides. Therefore, different approaches for controlling the accessibility of available over-thecounter (OTC) drugs for youths should be taken into consideration as a preventive measure against suicide attempts in children and adolescents. Lubin et al. ${ }^{17)}$ studied the importance of policy making in interventions directed at adolescent suicidal behavior. After the Israeli Defense Forces to changed their policy to reduce adolescent access to firearms, the suicide rates decreased significantly, by 
$40 \%{ }^{17)}$ In New Zealand, after more restrictive firearms legislation was introduced in 1992, the mean annual rate of firearm-related suicide decreased by $46 \%$ for the total population, $66 \%$ for youth, and $39 \%$ for adults. ${ }^{18)}$ The impact of policy was also evident among youth in this study. In Korea, there are laws limiting access to narcotics, cannabis, and psychotropic agents to protect adolescents from abusing these drugs. Additionally, many laws including the Minor Protection Law and the Toxic Chemicals Control Law are intended to protect adolescents from using alcohol, nicotine, hallucinogens, and so forth. However, there is no legal restriction on access to OTC drugs for adolescents. Furthermore, a new law that permits the sale of certain quasi-drugs in supermarkets took effect in July 2011 in Korea. A revised version of the Pharmaceutical Affairs Law permitting the sale of some OTC drugs including Tylenol and cold medicines in supermarkets is planned to be submitted to the National Assembly in Korea. Thus, more consideration should be given to the impact of these policies on the risk of suicide in youths.

The most probable reason for the increase in suicide rates in adolescents is pubertal onset of depression and substance abuse, which aggravates the risk of suicide. ${ }^{19)}$ The present study showed that depression was the most common psychiatric disorder in patients who attempted suicide. This is consistent with many other studies that have investigated the relationship between suicide and mood disorders. Children with mood disorders display a 4-to 5-fold higher likelihood of suicide attempts compared with children without mood disorders. Furthermore, even some symptoms of mood disorders, such as those apparent in adjustment disorder, were associated with an increased risk of suicidal behavior. ${ }^{20)}$ In adolescents, depression is highly associated with violence, ${ }^{21)}$ school refusal and truancy, ${ }^{22)}$ and substance abuse. ${ }^{23)}$ These factors are related to suicide behavior. Depressive symptoms such as avolition, irritability, and social isolation may negatively affect youths' potential for maintaining positive interpersonal relationships, which is a powerful protective factor during times of crisis. Therefore, prevention, early screening, and treatment of depression are effective ways to prevent suicidal behavior. ${ }^{24-26)}$

Moreover, increased impulsivity and immature decision-making ability are other possible factors in the increase in youth suicide. The decision-making process requires adequate maturation in the striatum (mediating approach), amygdala (representing avoidance), and prefrontal cortex (providing behavioral regulation). ${ }^{27)}$ These brain regions are known to be fully matured in young adulthood, which means that these regions remain immature during adolescence. Thus, behavior can be impulsive and uninhibited and may lack adequate consideration of the consequences of behavior. ${ }^{28)}$ By showing that $78.6 \%$ attempted suicide impulsively and $50 \%$ regretted their attempts, the present study suggests a role for biological vulnerability in suicide among adolescents.

In the present study, we also found that interpersonal conflict was the most common precipitating factor for suicidal behavior. This result is consistent with previous studies. ${ }^{29)}$ Dieserud et al. ${ }^{30)}$ investigated all general hospital-treated suicide attempters between 13 and 19 years of age $(\mathrm{n}=254)$ from 1984 to 2006 living in the municipality of Bærum, Norway. The most commonly reported antecedent was a relationship conflict (50.2\%), and the most commonly reported underlying reason was a dysfunctional family situation (43.6\%). In Taiwan, conflict with parents $(25 \%)$ was the most common, and conflicts with teachers or classmates (14\%) was the second-most common reason for suicide attempts. ${ }^{31)}$ For Turkish young people, negative social status among females, as evidenced by forced marriage, young marital age, low literacy, and honor killings, was a possible causative psychosocial factor. ${ }^{32)}$ These studies suggest that the precipitating factors for suicide may be different among cultures because of different psychosocial environments.

Our final point of discussion has to do with the lethality of the attempt. In the present study, the mean medical severity score $(3.1 \pm 1.0)$ was moderate. The risk score among these subjects $(7.5 \pm 2.0)$ corresponded to level 2 (low- moderate risk). The rescue score $(12.1 \pm 2.4)$ corresponded to level 4 (high-moderate likelihood of rescue). Thus, the lethality of subjects' scores included relatively low risk and high likelihood of rescue. This finding contrasts with findings in older groups, which showed more lethal suicidal behaviors. ${ }^{9,33,34)}$ This discrepancy might be due to differences in the choice of suicide methods between the two groups. As shown by the present study, children tend to choose less lethal drugs (e.g., acetaminophencontaining analgesics, aspirin, anti-histamines) compared with older groups (e.g., pesticides).

There are some limitations to the present study. Due to the small sample size, caution is advised when interpreting the findings of the present study. Adolescents and children constitute a relatively small part of the overall population who visit the emergency room for suicide attempts. Some attempters were excluded because the psychiatric interview was not possible or because they were poisoned by mistake and had no intention of committing 
suicide. Additionally, the present study only included suicide attempts involving drug overdose. Therefore, the findings cannot be generalized to suicide attempts using other methods. Finally, because the authors did not use structured diagnostic tools, the evaluation of psychiatric diagnosis may be limited even though trained psychiatry residents conducted the assessments.

In conclusion, children and adolescents who attempt suicide by overdosing with drugs tended to have depressive disorder, to experience interpersonal stress, and to choose easily accessible nonprescription drugs. They also tended to use less lethal methods and to have a high likelihood of being rescued. Specific policy efforts and social education programs are warranted.

\section{REFERENCES}

1. Miniño A. Mortality among teenagers aged 12-19 years: United States, 1999-2006. NCHS Data Brief 2010;(37):1-8.

2. Pompili M, Innamorati M, Vichi M, Masocco M, Vanacore $\mathrm{N}$, Lester $\mathrm{D}$, et al. Suicide prevention among youths. Systematic review of available evidence-based interventions and implications for Italy. Minerva Pediatr 2010;62:507-535.

3. Centers for Disease Control and Prevention (CDC). Suicide trends among youths and young adults aged 10-24 years--United States, 1990-2004. MMWR Morb Mortal Wkly Rep 2007;56:905-908.

4. Tang TC, Ko CH, Yen JY, Lin HC, Liu SC, Huang CF, et al. Suicide and its association with individual, family, peer, and school factors in an adolescent population in southern Taiwan. Suicide Life Threat Behav 2009;39:91-102.

5. Lahti A, Räsänen P, Riala K, Keränen S, Hakko H. Youth suicide trends in Finland, 1969-2008. J Child Psychol Psychiatry 2011;52:984-991.

6. McClure GM. Suicide in children and adolescents in England and Wales 1970-1998. Br J Psychiatry 2001;178:469474.

7. Cash SJ, Bridge JA. Epidemiology of youth suicide and suicidal behavior. Curr Opin Pediatr 2009;21:613-619.

8. Lee HS, Kim S, Choi I, Lee KU. Prevalence and risk factors associated with suicide ideation and attempts in Korean college students. Psychiatry Investig 2008;5:86-93.

9. Kim YR, Choi KH, Oh Y, Lee HK, Kweon YS, Lee CT, et al. Elderly suicide attempters by self-poisoning in Korea. Int Psychogeriatr 2011;23:979-985.

10. Im MY, Kim YJ. A phenomenological study of suicide attempts in elders. J Korean Acad Nurs 2011;41:61-71.

11. Kim HH. Pattern of childhood poisoning: a retrosepctive review [master's thesis]. Jeonnam:Jeonnam University;2009.

12. American Psychiatric Association. Diagnostic and Statistical manual of Mental Disorders. 4th ed text revised. Washington, DC:American Psychiatric Association;2000.

13. Linehan MM, Comtois KA, Brown MZ, Heard HL, Wagner A. Suicide Attempt Self-Injury Interview (SASII): development, reliability, and validity of a scale to assess suicide attempts and intentional self-injury. Psychol Assess 2006;18:303-312.

14. Weisman $\mathrm{AD}$, Worden JW. Risk-rescue rating in suicide assessment. Arch Gen Psychiatry 1972;26:553-560.

15. Cham E, Hall L, Ernst AA, Weiss SJ. Awareness and use of over-the-counter pain medications: a survey of emergency department patients. South Med J 2002;95:529-535.

16. Hornsby LB, Whitley HP, Hester EK, Thompson M, Donaldson A. Survey of patient knowledge related to acetaminophen recognition, dosing, and toxicity. J Am Pharm Assoc 2010;50:485-489.

17. Lubin G, Werbeloff N, Halperin D, Shmushkevitch M, Weiser M, Knobler HY. Decrease in suicide rates after a change of policy reducing access to firearms in adolescents: a naturalistic epidemiological study. Suicide Life Threat Behav 2010; 40:421-424.

18. Beautrais AL, Fergusson DM, Horwood LJ. Firearms legislation and reductions in firearm-related suicide deaths in New Zealand. Aust N Z J Psychiatry 2006;40:253-259.

19. Popova NK, Kulikov AV. Targeting tryptophan hydroxylase 2 in affective disorder. Expert Opin Ther Targets 2010;14: 1259-1271.

20. Kovacs M, Goldston D, Gatsonis C. Suicidal behaviors and childhood-onset depressive disorders: a longitudinal investigation. J Am Acad Child Adolesc Psychiatry 1993;32:8-20.

21. Yen CF, Ko CH, Yen JY, Tang TC, Chang YP, Cheng CP. Internalizing and externalizing problems in adolescent aggression perpetrators, victims, and perpetrator-victims. Compr Psychiatry 2010;51:42-48.

22. Egger HL, Costello EJ, Angold A. School refusal and psychiatric disorders: a community study. J Am Acad Child Adolesc Psychiatry 2003;42:797-807.

23. Goodman E, Huang B. Socioeconomic status, depressive symptoms, and adolescent substance use. Arch Pediatr Adolesc Med 2002;156:448-453.

24. Barrera AZ, Torres LD, Muñoz RF. Prevention of depression: the state of the science at the beginning of the 21st century. Int Rev Psychiatry 2007;19:655-670.

25. Cuijpers P, van Straten A, Smit F, Mihalopoulos C, Beekman A. Preventing the onset of depressive disorders: a metaanalytic review of psychological interventions. Am J Psychiatry 2008; 165:1272-1280.

26. Horowitz JL, Garber J. The prevention of depressive symptoms in children and adolescents: A meta-analytic review. $J$ Consult Clin Psychol 2006;74:401-415.

27. Ernst M, Romeo RD, Andersen SL. Neurobiology of the development of motivated behaviors in adolescence: a window into a neural systems model. Pharmacol Biochem Behav 2009;93:199-211.

28. Gogtay N, Giedd JN, Lusk L, Hayashi KM, Greenstein D, Vaituzis AC, et al. Dynamic mapping of human cortical development during childhood through early adulthood. Proc Natl Acad Sci U S A 2004;101:8174-8179.

29. Pandolfo S, Vázquez M, Más M, Vomero A, Aguilar A, Bello O. Suicide attempt in under 15 's: An experience in a Pediatric Emergency Depart. Arch Argent Pediatr 2011;109: 18-23.

30. Dieserud G, Gerhardsen RM, Van den Weghe H, Corbett K. Adolescent suicide attempts in Bærum, Norway, 1984-2006. Crisis 2010;31:255-264.

31. Chiou PN, Chen YS, Lee YC. Characteristics of adolescent suicide attempters admitted to an acute psychiatric ward in Taiwan. J Chin Med Assoc 2006;69:428-435.

32. Coskun M, Zoroglu S, Ghaziuddin N. Suicide rates among Turkish and American youth: a cross-cultural comparison. Arch Suicide Res 2012;16:59-72.

33. Schmidtke A, Sell R, Löhr C. Epidemiology of suicide in older persons. Z Gerontol Geriatr 2008;41:3-13.

34. Elnour AA, Harrison J. Lethality of suicide methods. Inj Prev 2008;14:39-45. 